\title{
Uso da informação por profissionais de vendas: estudo de caso em organização varejista brasileira de grande porte
}

\author{
Rômulo Braga Ramos ${ }^{I}$ \\ Luiz Antonio Joia ${ }^{I I}$ \\ Rodrigo Baroni de Carvalho ${ }^{I I I}$
}

${ }^{I}$ Fundação Getúlio Vargas, Rio de Janeiro, RJ, Brasil.

Mestrado em Gestão Empresarial.

${ }^{I I}$ Fundação Getúlio Vargas, Rio de Janeiro, RJ, Brasil.

Doutor em Ciências em Engenharia de Produção pela COPPE/UFRJ.

Engenheiro de Fortificação e Construção pelo Instituto Militar

de Engenharia (IME). Professor associado da Escola Brasileira

de Administração Pública e de Empresas da Fundação Getulio Vargas.

Professor associado (licenciado) da Universidade do Estado

do Rio de Janeiro (Faculdade de Engenharia).

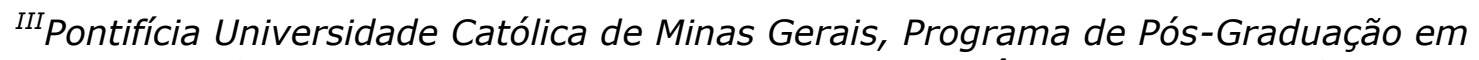
Administração, Belo Horizonte, MG, Brasil.Doutor em Ciência da Informação (UFMG / University of Toronto - Canadá). Professor Adjunto IV da Pontifícia Universidade Católica de Minas Gerais.

http://dx.doi.org/10.1590/1981-5344/3304

O objetivo deste trabalho é identificar como os profissionais de vendas do varejo usam a informação em sua rotina profissional. Foi desenvolvido um estudo de caso com quatro unidades de análise (lojas) em organização varejista brasileira de grande porte, tradicional no Nordeste do Brasil, com foco no lançamento de novo conceito de loja voltado para a tecnologia móvel, tendo as arenas do modelo do uso da informação (sensemaking, criação de conhecimento e tomada de decisão) e as influências ambientais de vendas como alicerces. $A$ análise documental compreendeu procedimentos operacionais, manuais e programas de desempenho, bem como o log do grupo Whatsapp dos lojistas. Foram entrevistados os gerentes das quatro lojas analisadas, além de vendedores, consultores, pessoal de apoio e executivos da organização, totalizando 12 
pessoas. Constatou-se que o profissional de vendas usa a informação em gradações diferentes entre as dimensões, com maior ênfase para o sensemaking e menor intensidade para a tomada de decisão.

Palavras-chave: Uso da Informação. Varejo. Sensemaking. Criação de Conhecimento. Tomada de Decisão.

\section{Information usage by sales professionals: a case study in a Brazilian large retail organization}

The main objective of this work is to identify how and why sales professionals in retail industry use information in their work routine. A case study was developed in a large retail organization situated in the Northeast region of Brazil, focusing on the deployment of a new store concept aimed at marketing mobile technology, using the dimensions of information use (sensemaking, knowledge creation and decision making) and environmental influences of salesforce as the major theoretical background. The documental analysis comprised organizational procedures, handbooks and performance program and also e-mails, presentations, intranet and Whatsapp log of the new store project group. Twelve people with different functions (managers, salespersons, support personnel and executive) from four stores were interviewed. The main findings are associated with the different levels of information usage in the three arenas with more emphasis on sense-making and less intensity on decision-making which is bounded by retail processes.

Keywords: Information Use. Retail. Sensemaking. Knowledge Creation. Decision Making.

Recebido em 09.10.2017 Aceito em 26.11.2018

\section{Introdução}

Ao longo dos anos, os estudos sobre informação ampliaram sua orientação e foco, abrangendo o comportamento dos usuários e o modo como as pessoas fazem uso da informação (CHOO, 2003). Um dos setores que mais pode se beneficiar de uma abordagem informacional que leve 
em consideração o usuário é o varejo. Neste setor, os custos trabalhistas representam uma significativa porcentagem dos custos totais do varejista e uma gestão efetiva da mão de obra pode produzir vantagem em relação aos competidores. Adicionalmente, a experiência que os clientes têm ao entrar numa loja é fruto das atividades de funcionários que selecionam mercadorias, dispõem o produto nas prateleiras e proveem informação e assistência (LEVY; WEITZ, 2012).

Como os demais setores da economia, o varejo também tem sido levado a ser mais eficiente em suas operações, reduzindo custos para manter margens competitivas, cenário este que provocou mudanças nas estratégias das empresas varejistas de grande porte no Brasil e estimulou a ocorrência de fusões, aquisições e processos de expansão (BRITO; VIEIRA, 2011). Para lidar com operações cada vez mais complexas, tornase inevitável que essas organizações invistam em gestão da informação e suas derivadas tecnológicas, processuais e comportamentais.

Por sua vez, Brown et al. (2005) destacam que influências ambientais externas e internas às organizações elevam as exigências quanto ao desempenho dos profissionais de vendas. Novos desenvolvimentos e tendências criam demandas e oportunidades que requerem adaptação e novas abordagens. Em muitas delas, esse profissional é requerido a processar, internalizar e gerir camadas crescentes de informação. Desse modo, a articulação de dimensões contextuais como o crescente volume de produção de informações na sociedade, o investimento das organizações para lidar com esse volume, as mudanças pelas quais passa o setor varejista brasileiro e as novas exigências feitas aos profissionais de vendas propicia um contexto relevante para o estudo das arenas de uso da informação no varejo brasileiro.

Este trabalho segue a recomendação de Wilson (2006) de que a investigação sobre informação deve ter foco e contexto delimitados, para que fatores cruciais possam ser identificados e analisados. Assim, este artigo busca compreender padrões de uso da informação pela força de venda de empresas varejistas. Dessa forma, o objetivo do artigo é identificar como e por que os profissionais de vendas usam a informação em sua rotina profissional, atentando para as limitações que cercam esses profissionais no desempenho de suas atividades. Para além desta introdução, o artigo está organizado da seguinte forma: a seção 2 contempla o referencial teórico com ênfase na explanação do modelo do uso da informação (Choo, 2003) e no uso da informação no setor de varejo, resultando na proposição do framework de pesquisa; a seção 3 detalha os procedimentos metodológicos; na seção 4 é feita a descrição do caso; os resultados são discutidos nas três dimensões do framework na seção 5; a conclusão apresenta a síntese dos resultados e propõe trabalhos futuros.

\section{Referencial teórico}

\subsection{Uso da informação nas organizações}


O uso da informação ocorre quando o indivíduo processa informação que o leva a mudar sua capacidade de agir. Esse uso geralmente envolve responder uma pergunta, resolver um problema, tomar uma decisão, negociar uma posição ou criar significado para uma situação (BERGERON et al., 2006). Quando se amplia essa discussão do âmbito individual para o plano das organizações, Choo (2003) argumenta que elas fazem uso da informação em três arenas distintas: sensemaking (criação de significado), construção de conhecimento e tomada de decisão. Apesar de geralmente tratados como processos organizacionais independentes, Choo (2003) acredita que as três atividades se alimentam mutuamente, permitindo visão holística do uso da informação. O sensemaking busca dar sentido às mudanças do ambiente externo num mundo dinâmico e incerto. A construção ou criação de conhecimento é a geração de novos conhecimentos por meio do aprendizado e da criação, organização e processamento das informações. Por fim, na tomada de decisão, as organizações avaliam as informações existentes para definir que rumos devem tomar.

A primeira arena de uso estratégico da informação - sensemaking pode ser traduzida pela seguinte pergunta (CHOO, 1999): o que os sinais externos do ambiente significam? A longo prazo, o sensemaking serve como estímulo para adaptação e perpetuidade da organização ( $\mathrm{CHOO}$, 2003), sendo feito retrospectivamente - já que só se pode dar sentido a ações ou fatos já ocorridos - e sendo precipitado por mudanças no ambiente, as quais criam descontinuidades no fluxo de experiência e atividades das pessoas e organizações (WEICK, 1995).

A segunda arena de uso estratégico da informação - construção de conhecimento - pode ser traduzida pela seguinte pergunta ( $\mathrm{CHOO}, 1999)$ : que conhecimento é preciso e como desenvolvê-lo? Nonaka et al. (1997) desenvolveram teoria que reconhece a necessidade de relacionamento sinérgico entre o conhecimento tácito e o conhecimento explícito para criação de novos conhecimentos. O conhecimento tácito é o conhecimento pessoal, difícil de formalizar ou comunicar para outros. Já o conhecimento explícito é o conhecimento formal, articulado objetivamente e mais facilmente transmissível entre indivíduos e grupos. Um terceiro tipo de conhecimento encontrado nas organizações é o conhecimento cultural (CHOO, 2003). Esse tipo de conhecimento desempenha o papel de oferecer um padrão de suposições compartilhadas aos membros da organização frente à realidade que os cerca.

Por fim, a terceira arena de uso estratégico da informação é a tomada de decisão. Ela pode ser traduzida pela seguinte pergunta ( $\mathrm{CHOO}$, 1999): que curso de ação é o melhor para a organização? Ainda que a tomada de decisão aparente ser um modelo baseado em pressupostos racionais, o princípio da racionalidade limitada desenvolvido por Simon e March (1993) impõe limites à capacidade da organização tomar decisões. Isso decorre das limitações cognitivas dos indivíduos que constituem essas organizações, quais sejam: hábitos, habilidades, conhecimento acumulado e valores e propósitos individuais que podem divergir dos objetivos da organização. As organizações direcionam as decisões de seus 
funcionários por meio do desenvolvimento de rotinas, procedimentos e valores que os ajudam a reduzir a incerteza e complexidade, diminuindo a necessidade cognitiva dos funcionários, e as informações necessárias para tomada de decisão (SIMON; MARCH, 1993).

Carvalho et al. (2007) desenvolveram um conjunto de variáveis que busca explicar, operacionalmente, cada uma dessas três arenas estratégicas do uso da informação, conforme exposto na Tabela 1. Tais variáveis foram adaptadas ao contexto desta pesquisa e se constituíram em referência para identificar o uso da informação pela força de vendas.

Tabela 1 - Usos da informação e a descrição de suas variáveis

\begin{tabular}{l|l}
\hline Arena Estratégica & \multicolumn{1}{c}{ Construto } \\
\hline \hline \multirow{4}{*}{ Sensemaking } & Comunicação do desempenho da organização \\
\cline { 2 - 2 } & Desenvolvimento de alianças e recursos dedicados à coleta de informações \\
\cline { 2 - 2 } & Oportunidades de discussão do ambiente externo \\
\cline { 2 - 2 } Conhstrução de & Comunicação de missão e valores \\
\cline { 2 - 2 } & Cultura de suporte à inovação \\
\cline { 2 - 2 } & Colaboração entre times \\
\cline { 2 - 2 } & Comunidades de prática \\
\cline { 2 - 2 } & Troca de experiências entre funcionários \\
\cline { 2 - 2 } & Programas de aprendizado \\
\cline { 2 - 2 } & Documentação de projetos e práticas \\
\cline { 2 - 2 } & Melhorias de processos \\
\hline \multirow{5}{*}{ Tomada de decisão } & Empowerment para tomada de decisão \\
\cline { 2 - 2 } & Rotinas e processos para tomada de decisão \\
\cline { 2 - 2 } & Visão retrospectiva \\
\cline { 2 - 2 } & Colaboração na tomada de decisão \\
\hline
\end{tabular}

Fonte: Adaptado de CARVALHO et al. (2007).

\subsection{Uso da informação no varejo}

O varejista é um intermediário que serve de ligação entre fabricantes e consumidores finais, atuando como um dos elos de um canal de marketing, e consistindo "em empresas engajadas basicamente na venda de mercadorias para consumo pessoal ou doméstico e na prestação de serviços ligados à venda de bens" (ROSENBLOOM, 2002, p. 62). Dentre as principais tarefas desempenhadas pelos varejistas estão: oferecer mão de obra e instalações físicas que permitam contato entre fabricantes e consumidores; dividir grandes quantidades em lotes do tamanho do consumidor; armazenar produtos; disseminar mensagens publicitárias; fornecer atendimento e interpretar a demanda do consumidor; reunir informações sobre clientes e concorrentes; e assumir riscos relacionados à operação do canal (KOTLER et al., 2006).

Para realizar cada uma dessas tarefas, o fluxo de informação interliga os membros do canal na distribuição de bens e serviços e envolve entidades distintas e prevê a troca de informações acerca de indicadores, prazos de entrega, condições comerciais e características dos produtos ao longo do canal (KOTLER et al., 2006). Esse ciclo regular de informações acontece também internamente às próprias organizações varejistas.

O uso da informação na atividade de vendas pode estar atrelado a objetivos quantitativos ou qualitativos. Os objetivos quantitativos envolvem volume de vendas mensais, ticket médio por venda, percentual 
de vendas a clientes frequentes, percentual de cadastros incorretos e perdas de estoque.

Já os objetivos qualitativos aferem a qualidade de processos ou procedimentos, tais como, o atendimento ao cliente, a abordagem de vendas, o conhecimento dos produtos, a aparência da loja, a disposição das mercadorias e a postura do vendedor (LEVY; WEITZ, 2012). A atuação da força de vendas tem sido afetada por influências externas e internas às organizações. De acordo com Brown et al. (2005), as influências externas mais relevantes são derivadas da maior exigência dos consumidores, da pressão exercida por competidores, das mudanças tecnológicas e de questões éticas e legais. Internamente à organização, os impactos na força de vendas são provocados pelo lançamento de novos produtos e serviços, fusões, redesenho de processos, novas estratégias de canais e a entrada em novos mercados.

\subsection{Framework para pesquisa}

O estabelecimento de um framework serve para identificar quem será ou não incluído no estudo, descrever que relações serão apresentadas e prover oportunidade para o pesquisador consolidar construtos gerais sob perspectivas e limites definidos (BAXTER; JACK, 2008). A representação gráfica do framework do uso da informação pela força de vendas de uma organização varejista (Figura 1) tem como base o modelo de uso da informação desenvolvido por Choo (2003) e as principais influências ambientais que afetam a força de vendas, de acordo com Brown et al. (2005).

Neste framework, destaca-se a distinção entre os ambientes externo e interno à organização. O ambiente externo possui esferas como clientes, competidores e fabricantes que enviam sinais e produzem ações e conhecimentos que são absorvidos pelo ambiente interno. Esses sinais, ações e conhecimentos são processados pela organização, gerando ainda mais elementos que afetam a força de vendas, como fusões, a necessidade de maior produtividade das equipes e a entrada em novos canais ou mercados. Todo esse conjunto de elementos é, então, processado pelas equipes de vendas, que têm suas limitações cognitivas e emocionais, e usam as informações para criar significado, construir conhecimento e tomar decisões.

Figura 1 - Representação gráfica do framework de pesquisa 


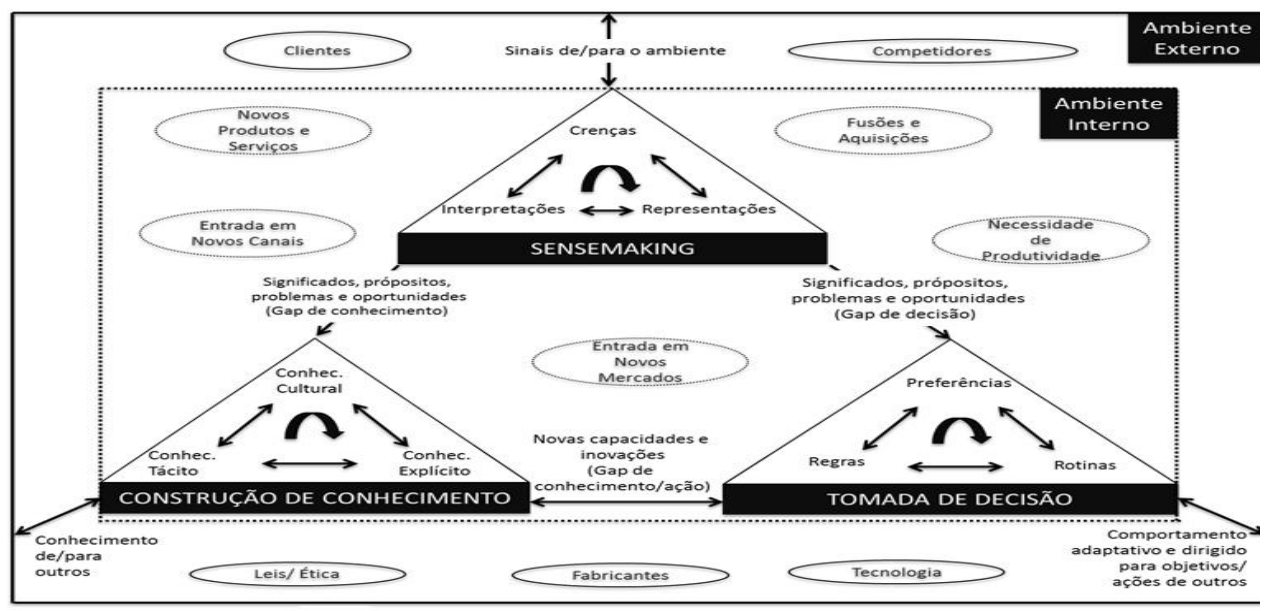

Fonte: Adaptado de CHOO (2003) incorporando elementos do varejo.

\section{Procedimentos metodológicos}

Nesta pesquisa, optou-se pelo estudo de caso único integrado (YIN, 2009), no qual se analisou o uso da informação pela força de vendas de uma empresa varejista brasileira de grande porte, com quatro unidades de análise, quais sejam, as quatro lojas do novo conceito voltado para a venda de tecnologia móvel (smartphones, tablets e acessórios). Este trabalho usou pesquisa de campo, com a coleta de dados nos locais de ocorrência do fenômeno; sendo documental, na medida em que foram levantados regras e procedimentos operacionais formais da empresa; e bibliográfico, por utilizar a literatura disponível sobre uso da informação, varejo e vendas.

Os documentos estudados foram procedimentos operacionais, manuais e programas de desempenho da empresa pesquisada. Os registros em arquivos avaliados foram arquivos digitais como e-mails, apresentações, a intranet da companhia e o log do grupo do projeto criado no aplicativo Whatsapp. Os artefatos físicos avaliados foram o layout das lojas, equipamentos de exposição, mobiliário, uniformes e peças decorativas do ambiente, as quais remetem à história e cultura da organização.

As entrevistas deste estudo foram abertas e realizadas ao longo de doze meses de desenvolvimento do projeto compreendidos entre setembro de 2015 e setembro de 2016, sendo três meses relativos à fase pré-operacional e nove meses relativos à abertura e operação das lojas. Foram entrevistados os gerentes das quatro lojas analisadas, além de vendedores, consultores, pessoal de apoio e executivos da organização, totalizando 12 profissionais.

A observação se deu de dois modos: direta e participante. A observação direta foi desenvolvida durante as visitas de campo, de modo a entender a dinâmica da loja, em especial o relacionamento entre a equipe de vendas e desta com os clientes. As dimensões chave de interesse nesse relacionamento eram o nível de cortesia com que os clientes eram atendidos, a capacidade de demonstração dos produtos e a padronização da loja. A observação participante, por sua vez, foi 
viabilizada pela capacidade que os pesquisadores tiveram de participar e alterar processos vigentes na organização.

A estratégia desenvolvida para coletar informações junto à força de vendas contemplou visitas semanais às quatro lojas. Nestas visitas, houve a oportunidade de conversar com os funcionários, questionar-Ihes como estavam as vendas, aspectos da loja fora do padrão esperado e coletar informações sobre o desempenho dos produtos e da concorrência. A partir daí, eram observados quais os principais elementos do discurso de cada colaborador e com que intensidade tais elementos se repetiam nas observações dos outros profissionais distribuídos pelas lojas.

A estratégia desenvolvida para coletar as informações junto à força de vendas passava por visitas semanais às lojas. Em cada uma das visitas às quatro lojas, os pesquisadores ficavam por cerca de uma hora realizando questionamentos acerca de aspectos da loja fora do padrão esperado, bem como estimulavam que a equipe Ihes informasse o que esta poderia fazer para melhorar as vendas, a despeito de outras deficiências organizacionais em discussão. Ao questionar o que cada vendedor ou gerente de loja poderia oferecer de contribuição adicional à melhoria das vendas, a observação se concentrava em como o profissional entrevistado percebia a sua capacidade de gerar resultados, quais eram os principais elementos do seu discurso, e com que intensidade tais elementos se repetiam nas observações dos outros profissionais espalhados pelas lojas. Assim como era feito com os profissionais do setor administrativo, as reflexões, observações, e insights relevantes e pertinentes ao estudo eram registrados pelo pesquisador em banco de dados criado para o projeto.

Por fim, foi realizado levantamento de dados estatísticos do desempenho de cada loja, comparando-se os resultados anteriores e posteriores à implementação do novo conceito. Tais informações serviram de apoio para o processo metodológico, não devendo ser encaradas como medidas operacionais dos construtos, mas apenas como componente adicional da investigação. Foi construída base de dados registrando o passo a passo da pesquisa e as principais informações levantadas. Adicionalmente, foram utilizadas múltiplas fontes de evidência na coleta de dados, bem como a revisão do relatório por informantes-chave.

A partir das recomendações de Baxter e Jack (2008), foi elaborado workflow do procedimento metodológico, identificando as etapas do processo (Figura 2).

Figura 2 - Workflow dos procedimentos metodológicos 


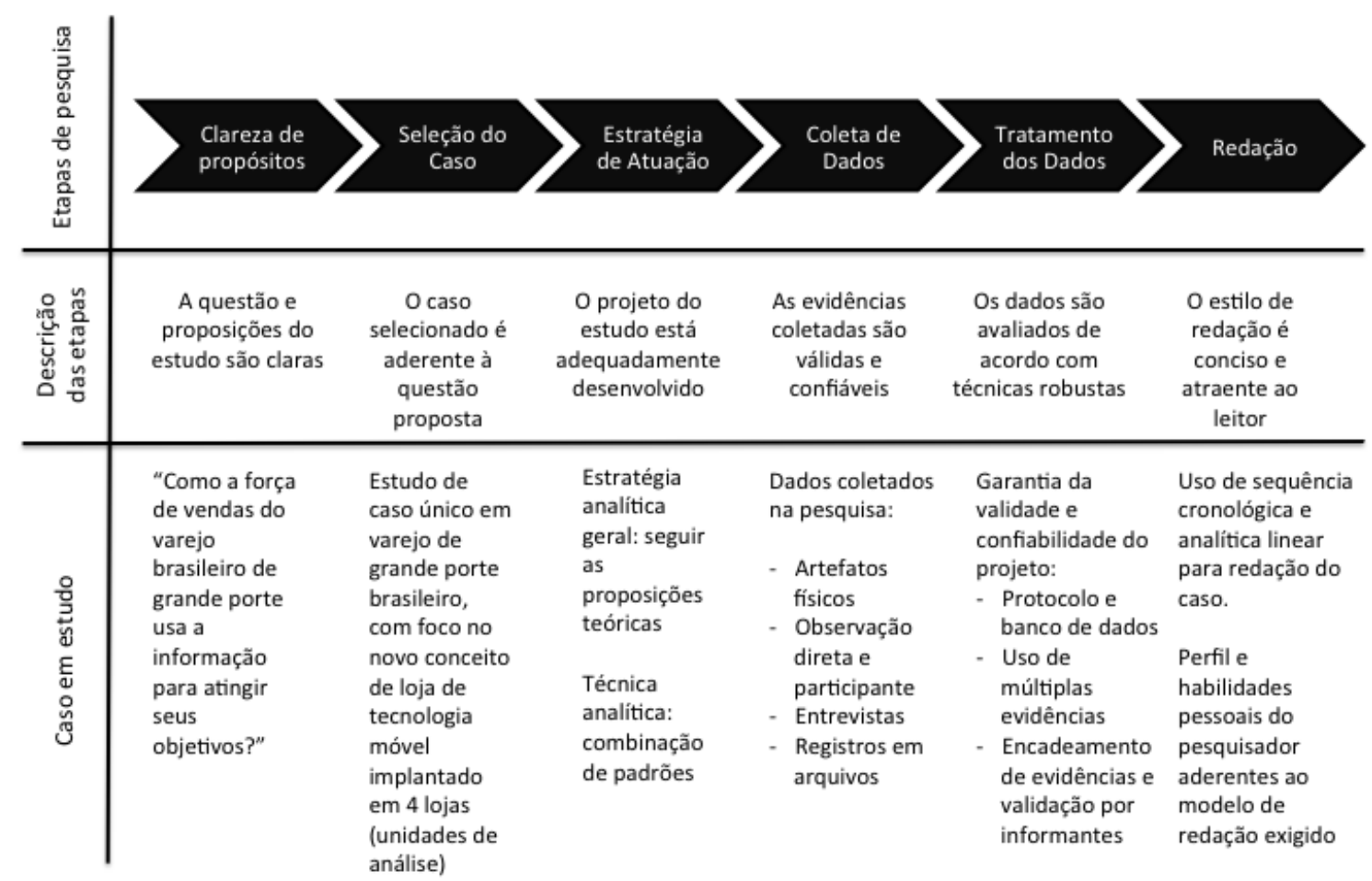

Fonte: Elaborado pelos autores a partir de BAXTER; JACK (2008).

\section{Descrição do caso}

\subsection{Projeto de novo conceito de loja da Eletromais}

O estudo de caso avaliou o desenrolar da implementação do novo conceito de loja para comercialização de smartphones, tablets e acessórios de uma grande rede varejista brasileira, chamada pelo nome fictício de EletroMais por questões de sigilo. A empresa possui mais de 50 anos, cerca de 200 lojas na Região Nordeste do Brasil e faturamento superior a $\mathrm{R} \$ 1$ bilhão por ano. O mix de produtos da rede inclui TVs, celulares, eletrodomésticos, móveis, geladeiras e fogões. A EletroMais é reconhecida por ter seu público alvo nas camadas de menor poder aquisitivo, pagamento parcelado e veiculação maciça de propaganda.

A equipe de uma loja típica EletroMais inclui gerente, subgerente, vendedores, caixas, estoquistas e auxiliares de serviços gerais. O perfil da equipe é de escolaridade de nível médio, com alto turnover ao redor de $40 \%$, sendo calculado pela divisão do número total de colaboradores desligados pelo número total de funcionários. Os vendedores e o gerente recebem remuneração variável, respectivamente, de acordo com as vendas individuais ou totais da loja. As outras funções administrativas recebem o piso da categoria.

Desde o surgimento da telefonia celular, a EletroMais teve foco na comercialização de aparelhos celulares baratos. Tais aparelhos são geralmente expostos desligados em balcões fechados e os clientes só têm acesso aos aparelhos por meio da intervenção dos vendedores. Os 
cartazes de preço não apresentam informações técnicas, nem há catálogo eletrônico com benefícios dos aparelhos disponíveis para consulta dos vendedores.

Ao chegar na EletroMais, um novo vendedor recebe treinamento de boas-vindas de uma semana, composto basicamente da história da organização, sua missão e valores, sistemas, serviços e habilidades comportamentais. Em geral, o treinamento inicial não é suficiente para capacitação da equipe, ainda que o método de vendas estimule a padronização do atendimento. Desse modo, é comum que os novos vendedores só recebam a sua senha para cadastro de vendas após 30 dias de experiência, nos quais o recém-chegado em loja é acompanhado por um vendedor de maior experiência. Em sua progressão de carreira, os vendedores que apresentam bom histórico de resultados são convidados a participar de programas de formação de liderança.

Se nos treinamentos formais da empresa não há muitas oportunidades para aprendizado sobre aparelhos celulares, a empresa possui sistemas que proveem informações de negócios atualizadas periodicamente. $\mathrm{Na}$ intranet corporativa, podem ser encontrados documentos acerca de 90 rotinas administrativas. Os vendedores geralmente acessam os sistemas para registro de ponto, consulta de preços, disponibilidade de estoque e relatórios de desempenho. A navegação na Internet é restrita em loja e apenas o gerente da loja possui e-mail corporativo.

Os fornecedores também buscam aproximação com os vendedores do varejista por meio de seus promotores em loja, que transmitem informações, realizam treinamentos de novos produtos, promovem campanhas de venda ou mesmo distribuem pequenos brindes. A prática de atendimento corrente na organização aponta para baixo nível de informação acerca dos produtos vendidos e foco nos produtos mais baratos, nas promoções vigentes, e na venda de serviços agregados como garantia estendida. A comunicação entre o departamento comercial (responsável pelo mix e preços de produtos) e o departamento de vendas (responsável pela operação de loja) é limitada, o que atrapalha a circulação de informações sobre produtos e lançamentos. Nesse cenário, questionamentos mais complexos de clientes são usualmente repassados para os promotores dos fabricantes, que oferecem apoio no atendimento nas principais lojas da rede. Já nas lojas onde não há promotores, o conhecimento dos produtos depende da iniciativa própria dos vendedores.

Nos últimos anos, o segmento de telefonia celular aumentou a sua representatividade no faturamento total das cadeias varejistas de eletroeletrônicos do Brasil (IDC, 2014). Percebendo esse cenário de intensas mudanças no ambiente externo e de lacunas no ambiente interno para atendimento a seu cliente, a EletroMais decidiu desenvolver um novo conceito de loja de tecnologia. Para tanto, contratou, em 2015, quatro profissionais com experiência no segmento varejista de telefonia celular, que passaram a compor a diretoria de novos negócios da empresa. Após pesquisas de mercado, o novo conceito de loja se baseou nos seguintes pilares: nova marca de nome Mobile (nome fictício criado nessa pesquisa 
para fins de preservação do sigilo da organização); mix de produtos e serviços diferenciados; meios de pagamento diversos; atendimento dos clientes por consultores mais capacitados; e ambiente moderno que permitisse a experimentação dos produtos pelos consumidores.

Os consultores tinham a missão de oferecer atendimento mais completo, apoiar o gerente da loja em demandas técnicas e supervisionar a equipe de vendedores de tecnologia. Para dar suporte à qualificação da equipe de vendas, a grade inicial de treinamento foi acrescida de mais duas semanas, com espaço para treinamento do novo conceito e para cada fabricante apresentar as funcionalidades dos seus aparelhos. Para o lançamento da Mobile, foram criados, então, quatro modelos de loja para teste: Dedicado, Compartilhado, Loja em Loja e Quiosque.

Cada modelo apresenta diferenças quanto ao valor do investimento envolvido, grau de intervenção em loja, necessidade de equipe e pontos de exposição de produtos (Tabela 2). Os modelos seriam testados em quatro pontos de venda já existentes, de modo que a organização percebesse qual deles traria o melhor resultado, expandindo o número de lojas ao longo dos meses seguintes.

$\mathrm{Na}$ fase pré-operacional, que durou cerca de três meses, a equipe do projeto teve total autonomia para planejar uma série de iniciativas para o lançamento da Mobile, tendo a coleta de informações sobre a cultura e o passado da organização sido realizada, principalmente, a partir de entrevistas com os colaboradores mais antigos. Por outro lado, mesmo com autonomia oferecida durante a fase pré-operacional, aconteceram ruídos entre a equipe do projeto e a equipe de vendas da EletroMais.

A criação do cargo de consultor e o processo seletivo rigoroso geraram controvérsias internas e queixas dos gerentes das lojas, especialmente quando muitos vendedores não foram escolhidos pela equipe do projeto para o cargo de consultor. Adicionalmente, críticas surgiram devido à introdução de uma nova marca em detrimento da marca EletroMais, e pelas intervenções físicas nas lojas que receberiam o novo conceito.

Tabela 2 - Modelos de loja de tecnologia da EletroMais

\begin{tabular}{|c|c|c|c|}
\hline Modelo de Loja & Conceito & Modelo de Gestão & Mix de produtos \\
\hline Dedicada & "Loja independente da marca Mobile & $\begin{array}{l}\text { Exclusiva. Gerente de } \\
\text { loja dedicado àquela } \\
\text { unidade }\end{array}$ & $\begin{array}{l}\text { Apenas } \\
\text { smartphones, } \\
\text { tablets e } \\
\text { acessórios }\end{array}$ \\
\hline Compartilhada & $\begin{array}{l}\text { Divisão da Loja EletroMais em dois } \\
\text { ambientes, como se fossem lojas } \\
\text { separadas, e adoção da nova marca de } \\
\text { tecnologia para público externo }\end{array}$ & \multirow{3}{*}{$\begin{array}{l}\text { Compartilhada. } \\
\text { Gerente da loja é } \\
\text { responsável pelos } \\
\text { dois ambientes de } \\
\text { loja }\end{array}$} & \multirow{3}{*}{$\begin{array}{l}100 \% \text { do mix de } \\
\text { produtos da } \\
\text { EletroMais } \\
\text { (convivência com } \\
\text { outras linhas) }\end{array}$} \\
\hline Loja em Loja & $\begin{array}{l}\text { Loja EletroMais segregada em dois } \\
\text { ambientes, e adoção de novo layout para a } \\
\text { área de tecnologia }\end{array}$ & & \\
\hline Quiosque & $\begin{array}{l}\text { Implantação de quiosque na Loja } \\
\text { EletroMais, sem alteração mais incisiva das } \\
\text { características da loja }\end{array}$ & & \\
\hline
\end{tabular}

Fonte: Dados da pesquisa.

\subsection{Resultados da Mobile}


As lojas foram abertas em novembro de 2015. O lançamento das lojas produziu resultados de vendas significativos: nas Lojas Mobile, a venda de tecnologia móvel cresceu $91,7 \%$ frente ao mesmo período do ano anterior, ante crescimento de $24,9 \%$ nas Lojas EletroMais. Mesmo com o sucesso inicial, logo após a abertura das lojas, mudanças em relação ao planejamento inicial começaram a acontecer, principalmente, 0 esvaziamento das funções da equipe do projeto, com a gestão das novas lojas sendo absorvida pelos processos e equipes já existentes na EletroMais.

O modelo de atuação especialista previsto no projeto tinha por foco a comercialização de produtos de maior valor agregado, acima do ticket médio normalmente comercializado pela organização. O modelo de atuação generalista da equipe de vendas da EletroMais tinha por foco a comercialização de aparelhos de ticket médio mais baixo, agregado a serviços como garantias e seguros. A falta de uma melhor integração entre as equipes do projeto e de gestão das lojas gerava descompasso de orientações em campo, conflitos nas lojas e dificuldades no estabelecimento de metas comuns.

Ao longo dos primeiros dois meses de lojas abertas, as discussões sobre desempenho eram realizadas em reuniões entre os gerentes de loja, o gerente regional de vendas da EletroMais, a equipe do projeto e os principais consultores das lojas. Adicionalmente, informações eram trocadas por meio de grupo criado no Whatsapp por iniciativa de uma consultora, em ação independente da orientação organizacional e sem moderação institucional. Nesse grupo, a equipe de vendas sinalizava problemas e oportunidades em loja, e, por outro lado, a equipe do projeto distribuía informações importantes sobre temas comerciais. Essa prática de reuniões presenciais e troca de informações via redes sociais foi se perdendo ao longo do tempo, à medida que a equipe do projeto encontrava mais dificuldades em se relacionar com a equipe de gestão da EletroMais.

No período entre fevereiro e abril/2016, quando problemas de abastecimento afetaram o faturamento, foram geradas cobranças incisivas pelas equipes de loja via Whatsapp. Devido às limitações da comunicação via rede social para tratamento de questões de maior complexidade e seus conflitos, os gestores passaram a evitar a ferramenta, preferindo tratar tais assuntos por telefone ou pessoalmente. Como consequência, a comunicação via Whatsapp para um público amplo foi se perdendo, e, de acordo com as afinidades, subgrupos foram sendo estabelecidos.

Com suspensão da linha de crédito exclusiva, as lojas Mobile passaram a ser abastecidas com os mesmos produtos comprados para a EletroMais, o que afetou a concepção inicial de que a Mobile seria uma loja atualizada com produtos de todas as marcas e os principais lançamentos do mercado. A linha de dispositivos da Apple foi retirada do mix, bem como novas compras de acessórios não foram mais realizadas.

A venda pelo plano de pagamento à vista se mostrou um sucesso em termos de faturamento, com crescimento da participação dessa modalidade em mais de 10 pontos percentuais, mas um fracasso em 
termos de margem, já que os vendedores praticavam o maior desconto possível ou aproveitavam os preços mais baixos para estimular a venda de serviços. Isso levou à descontinuidade da política de desconto à vista após três meses de aplicação, retornando ao modelo usualmente praticado pela EletroMais, em parcelas sem juros, o que garantia maior rentabilidade para a linha de produtos.

O pilar de atendimento consultivo também não foi realizado de acordo com o planejamento. A função de consultor não teve continuidade e vagas que surgiram pela movimentação de pessoal não foram repostas. O treinamento de três semanas também não teve continuidade e a grade aplicada para novos vendedores voltou a ser de uma semana. O modelo de treinamento mais robusto, que funcionou adequadamente quando as lojas não estavam abertas, não se sustentou, seja porque não havia número suficiente de vendedores para abertura de turmas junto aos fabricantes, seja porque treinamentos de produtos implicavam na redução do número de atendentes em loja, o que poderia afetar as vendas.

A falta de maior conhecimento técnico afetava diretamente 0 processo de vendas; por outro lado, o conhecimento adquirido por meio da experiência nas Lojas EletroMais era valorizado. A equipe de vendas demonstrou muita preocupação com o binômio "preço-produto". A discussão sobre o ambiente externo limitava-se aos temas de preços e abastecimento de produtos frente às práticas da concorrência. Usualmente, eram realizadas visitas às lojas dos concorrentes para monitoramento, com transmissão de fotos de encartes, notas fiscais e cartazes com preços mais baixos via Whatsapp.

A mudança de ambiente testada no projeto foi o pilar mais eficiente. Os clientes podiam interagir e manusear os aparelhos. Para criar os cartazes de preço com as características dos produtos, foi desenvolvido módulo de especificação técnica alocado na intranet corporativa, institucionalizando-se as características dos produtos por meio de ferramentas informatizadas.

As primeiras quatro lojas conceito serviram de experimento para a modernização das outras lojas da rede. As melhorias identificadas foram discutidas internamente e junto a fornecedores, servindo de insumo para ajustes nos cinco pilares do novo conceito de loja. A preferência da organização se deu pelo modelo de Quiosque, o que permitiria a modernização das outras lojas, sem a necessidade de maiores investimentos. Para o processo de expansão, foram desenvolvidos mobiliários e equipamentos de exposição de menor custo, a partir do conhecimento desenvolvido nos primeiros quiosques. Adicionalmente, foi criado manual detalhado com instruções do processo de montagem. Finalmente, da equipe de projeto, apenas um dos gerentes continuava na organização após agosto/2016.

\section{Discussão dos resultados}

No caso estudado, podem-se observar fatores do ambiente interno afetando a força de vendas da EletroMais como, por exemplo, a inclusão 
de smartphones sofisticados e acessórios no mix de produtos. Ademais, o lançamento da Mobile representou uma mudança no modelo de atendimento ao cliente na rede. A presença da equipe de projeto, composta por executivos e consultores advindos de fora da organização, influenciou $o$ modo como funcionários perceberam a iniciativa, principalmente pela promessa de maior produtividade na linha de tecnologia móvel. Desse modo, foi possível validar a premissa do framework de que os ambientes interno e externo afetam a atuação da força de vendas, como a seguir apresentado.

\subsection{Dimensão Sensemaking}

Para avaliar o uso da informação para criação de significado, foram utilizadas as variáveis adaptadas de Carvalho et al. (2007) e evidências encontradas na coleta de dados, conforme Tabela 3. Das arenas estratégicas de uso da informação pela força de vendas (CHOO, 2003), a criação de significado foi a mais evidente neste estudo de caso. A organização tem uma abordagem sistemática para comunicar sua missão, valores, significados compartilhados e crenças comuns. Desde o momento em que chegam na empresa, os vendedores são apresentados à história da empresa, sua missão e valores no treinamento inicial.

Tabela 3 - Evidências de sensemaking identificadas no caso Mobile

\begin{tabular}{l|l}
\hline \multicolumn{1}{c|}{ Construto ajustado } & \multicolumn{1}{c}{ Evidências identificadas } \\
\hline \hline Comunicação de missão e valores & $\begin{array}{l}\text {. Treinamento inicial } \\
\text {. Propaganda maciça }\end{array}$ \\
\hline Comunicação do desempenho da organização & $\begin{array}{l}\text {. Acessibilidade a ferramentas de desempenho } \\
\text {. Ausência de discussões sobre perfil de clientes }\end{array}$ \\
\hline $\begin{array}{l}\text { Desenvolvimento de alianças e recursos } \\
\text { dedicados à coleta de informações }\end{array}$ & $\begin{array}{l}\text {. Presença dos promotores dos fabricantes nas lojas } \\
\text {. Visitas a lojas dos concorrentes }\end{array}$ \\
\hline Oportunidades de discussão do ambiente externo & $\begin{array}{l}\text {. Binômio preço-produto } \\
\text {. Distância entre departamentos comercial e de vendas }\end{array}$ \\
\hline
\end{tabular}

Fonte: Dados da pesquisa.

O poderio de vendas da organização também passa pela força da marca, presente há mais de 50 anos no mercado e reforçada pela publicidade maciça. A criação de uma nova marca como a Mobile, ao mesmo tempo em que atraiu profissionais de fora, causou estranhamento àqueles mais conservadores, evidenciado pela comemoração do gerente da Loja Compartilhada quando da decisão de retomar mais espaço para a marca EletroMais em sua loja.

A comunicação do desempenho da organização é acessível por meio de diferentes ferramentas. Em loja, um vendedor pode saber, a qualquer momento, qual o seu volume de vendas. Se os indicadores de vendas, margens e estoque são facilmente acessíveis e alvo de discussões diárias, há oportunidades para mais discussões acerca do perfil dos clientes e qualidade de atendimento.

A organização não desenvolve alianças e processos estruturados para a coleta de informações do mercado, mas a presença de promotores 
dos fabricantes e a proximidade dos concorrentes ajuda a força de vendas a desenvolver ações tácitas de inteligência competitiva. Nesse processo, a equipe coleta informações, estabelece comparações sobre a competitividade de mercado e compartilha informações com áreas centrais. Essa verificação das condições do ambiente leva a discussões calcadas, basicamente, em preço e produto, o que é agravado pela distância entre as áreas comercial e de vendas, o que dificulta a elevação e nível do debate organizacional.

\subsection{Dimensão de construção de conhecimento}

Para avaliar o uso da informação para construção de conhecimento, adotaram-se as variáveis adaptadas de Carvalho et al. (2007) e evidências da coleta de dados (Tabela 4).

Tabela 4 - Evidências de construção de conhecimento identificadas no caso Mobile

\begin{tabular}{l|l}
\hline \multicolumn{1}{c|}{ Construto ajustado } & \multicolumn{1}{c}{ Evidências identificadas } \\
\hline \hline Cultura de suporte à inovação & $\begin{array}{l}\text {. Novo conceito de loja para venda de tecnologia móvel } \\
\text {. Contratação de executivos do mercado } \\
\text {. Dificuldade na venda de acessórios }\end{array}$ \\
\hline Colaboração entre times & . Dificuldade de interação entre equipe de operações e do projeto \\
\hline Comunidades de prática & $\begin{array}{l}\text {. Troca de informações não institucional no Whatsapp } \\
\text {. Vivência e experiência como limites para venda } \\
\text {. Presença de promotores nas lojas }\end{array}$ \\
\hline Troca de experiências entre & . Boas vindas em loja por funcionários mais experientes \\
funcionários & . Elevado turnover e perda de conhecimento tácito \\
\hline Programas de aprendizado & . Treinamento de boas vindas \\
& . Programas de liderança \\
\hline Documentação de projetos e & . Descontinuidade dos treinamentos de produtos \\
\hline práticas & . Aificuldade de explicitar conhecimento de loja \\
& . Rotinas administrativas na intranet \\
\hline Melhorias de processos & . Novo sistema de cartaz de preço \\
\hline & Fonte: Dados da pesquisa.
\end{tabular}

A construção de conhecimento talvez tenha sido a arena estratégica mais problemática. A empresa investiu para criar um novo modelo de loja que visava preencher um gap junto aos seus clientes, em processo de geração de conhecimento iniciado pela contratação de profissionais de mercado. A autonomia dada a esses profissionais para a implementação do conceito causou ruídos com as equipes já presentes na organização, mas não afetou o lançamento das lojas. Adicionalmente, percebe-se o esforço da organização em desenvolver programas de aprendizado, capacitando vendedores com treinamento inicial e oferecendo programas de liderança para aqueles que mais se destacam, evidenciando processos de transformação de conhecimento explícito em tácito (NONAKA et al., 1997).

Contudo, isso não parece ter sido suficiente, já que a organização não possui repositórios de informação dos produtos que comercializa. A força de vendas aprende na prática sobre os produtos, principalmente pela presença de promotores ou funcionários mais antigos que thes repassam conhecimento. Assim, o limite da capacidade de vendas do 
profissional parece ser muito influenciado pela sua experiência e vivência com os produtos que comercializa.

Adicionalmente, na medida em que se identificam elevadas taxas de turnover na Mobile, infere-se o volume de conhecimento tácito que é desperdiçado a cada demissão de funcionário, e a dificuldade que a organização apresenta na transformação do conhecimento tácito existente em loja em conhecimento explícito (NONAKA et al., 1997). Nesse cenário, os promotores dos fabricantes assumem posição relevante, especialmente pela capacidade de oferecer explicações para aparelhos mais sofisticados. Como não há promotores em todas as lojas em todo o tempo, oportunidades de vendas são perdidas pela falta de compilação e estruturação desse conhecimento.

No caso da Mobile, observou-se que a organização ofereceu treinamentos dos fabricantes antes da abertura das lojas, mas não encontrou a fórmula de manutenção desse procedimento, voltando a atuar conforme as práticas correntes da EletroMais. Essa lacuna poderia ter sido preenchida se a organização tivesse investido em mais processos internos com uso de tecnologia, como foi feito no desenvolvimento do módulo de especificações técnicas para cartazes de preço ou mesmo na publicação das rotinas administrativas na intranet. Ainda que não apresente comunidades de prática formais, o uso de ferramentas sociais para troca de informações, como o Whatsapp, é realidade, mesmo que as relações no mundo virtual não sejam institucionalizadas em processos da companhia.

O conhecimento cultural também se mostrou relevante. Mesmo com um novo projeto e a presença de diversos membros novos na equipe, o patamar de serviços nas Lojas Mobile se manteve praticamente inalterado. Por outro lado, dada à falta de cultura na venda de acessórios, a participação desse produto teve baixa participação no faturamento total. Assim, de algum modo, a influência do sensemaking pode ser sentida na construção de conhecimento. Se o binômio "preço-produto" é o principal vetor de configuração da realidade e o papel do próprio vendedor parece ser minimizado, o esforço que a equipe despenderá para construir conhecimento acerca de novos produtos não faz muito sentido.

\subsection{Dimensão de tomada de decisão}

Para avaliar o uso da informação para tomada de decisão, recorrese, mais uma vez, às variáveis adaptadas de Carvalho et al. (2007) e evidências encontradas (Tabela 5).

Tabela 5 - Evidências de tomada de decisão identificadas no caso Mobile

\begin{tabular}{l|l}
\hline \multicolumn{1}{c|}{ Construto ajustado } & \multicolumn{1}{c}{ Evidências identificadas } \\
\hline $\begin{array}{l}\text { Empowerment para tomada de } \\
\text { decisão }\end{array}$ & $\begin{array}{l}\text {. Inflexibilidade dos processos de venda } \\
\text {. Dificuldade na garantia de padrões de loja }\end{array}$ \\
\hline $\begin{array}{l}\text { Rotinas e processos para tomada } \\
\text { de decisão }\end{array}$ & . Preços e descontos determinados em áreas centrais \\
\hline Visão retrospectiva & . Ausência de documentação relativa a projetos anteriores \\
\hline Tomada de decisão colaborativa & $\begin{array}{l}\text {. Decisão da equipe de vendas limitada ao produto a oferecer e cliente a atender } \\
\text {. Fim natural do grupo do Whatsapp como espaço para discussões }\end{array}$ \\
\hline
\end{tabular}


Fonte: Dados da pesquisa.

Decisões tomadas pela equipe do projeto foram baseadas em conversas com colaboradores mais antigos, já que não se observou a existência de documentação de projetos passados. Por outro lado, a possibilidade de tomada de decisão no âmbito da atividade de vendas parece ser restringida pela inflexibilidade dos processos comerciais estabelecidos pela organização. Um vendedor pode até decidir se será proativo em sua abordagem de atendimento ao cliente; contudo, ele tem pouca margem de manobra para ajustar o preço de determinado produto às condições de mercado ou à característica de cada cliente.

Quando a Mobile estabeleceu a possibilidade do vendedor tomar decisões autônomas no desempenho de suas atividades, entregando a ele alguma flexibilidade na determinação de preços, o que se percebeu é que o vendedor oferecia o menor preço possível ou incluía serviços, de forma aderente ao paradigma "preço-produto", mesmo com margens menores para a organização. Nesse sentido, a busca de alternativa satisfatória para resolução de problemas se orienta para práticas habituais, refletindo o treinamento, a experiência e os objetivos dos decisores (SIMON; MARCH, 1993).

Outro momento em que a força de vendas pode tomar uma decisão ocorre quando do pedido de aconselhamento de um cliente. É comum o vendedor demonstrar aqueles produtos com os quais tem mais familiaridade ou aqueles que se encontram em promoção. Outro episódio interessante ocorreu quando os questionamentos realizados pela equipe, no Whatsapp, aumentaram com os eventuais problemas de abastecimento, e não foram tratados via rede social, o que gerou desestímulo ao uso desse grupo como ambiente de discussões. Isso parece evidenciar o baixo nível de estímulo ao processo decisório colaborativo e a dificuldade da organização em lidar com indivíduos e grupos que expressem abertamente suas opiniões.

\section{Conclusões}

Entende-se que uma contribuição oferecida por este trabalho se concentra na identificação de que se as três arenas estratégicas descritas por Choo (2003) são fins para o uso da informação pela força de vendas, a intensidade com que isso ocorre varia, pois verificou-se que o uso da informação para sensemaking é bastante intenso. A partir do contexto em que se situa a EletroMais, a força de vendas da Mobile desenvolveu parâmetros próprios para o desempenho do seu papel profissional. Esses parâmetros são influenciados, principalmente, pela percepção da variável "preço-produto" e servem para a força de vendas se posicionar frente às demandas do ambiente (WEICK, 1995).

Por seu turno, na dimensão da construção de conhecimento, percebeu-se a dificuldade que a força de vendas da Mobile tem em construir novos aprendizados. Os padrões vigentes na EletroMais são repetidos: o conhecimento cultural garante a manutenção dos patamares 
de vendas de serviços, mas sufoca as vendas de acessórios. As experiências pessoais vividas, associadas ao conhecimento obtido pela transmissão de promotores e funcionários mais antigos, formam manancial rico de conhecimento, principalmente tácito, que sustenta a atuação do vendedor no ponto de venda.

Por outro lado, há dificuldade na transposição organizada de conhecimento tácito para explícito, com o domínio de conhecimento estruturado dos produtos comercializados ficando sob poder dos fabricantes. A tentativa de desenvolvimento de novos processos de treinamento não se sustentou a longo prazo e, à medida em que o turnover da equipe é elevado, parte do conhecimento tácito não é retido. Assim, verifica-se que o uso da informação para construção de conhecimento é menos intenso que na arena de sensemaking (NONAKA et al., 1997).

Por fim, na arena de tomada de decisão, percebeu-se que as regras e processos comerciais estabelecidos na rede varejista não oferecem condições para que a equipe desenvolva ações decisórias autônomas. $O$ campo de ação é limitado à atitude do próprio vendedor em loja e à recomendação de produtos a clientes. Os processos desenvolvidos pela organização estimulam que a equipe atue no cumprimento de rotinas e regras operacionais pré-estabelecidas pelas áreas centrais, com baixa complexidade nas decisões (SIMON; MARCH, 1993). Com isso, para que a organização consiga prestar bom atendimento a seus clientes, cresce a importância do adequado desenho e suporte de processos pelas áreas centrais. Concluiu-se que o uso da informação para tomada de decisão é o menos intenso em relação às três arenas estratégicas de Choo (2003).

Desse modo, deve-se adaptar o framework desenvolvido na seção de referencial teórico para considerar o uso da informação nas diferentes arenas, conforme proposto na Figura 3, indicando-se os elementos que compõem o ambiente externo e interno que envolvem a força de vendas no seu dia-a-dia.

Figura 3 - Uso da informação pela força de vendas do varejo 


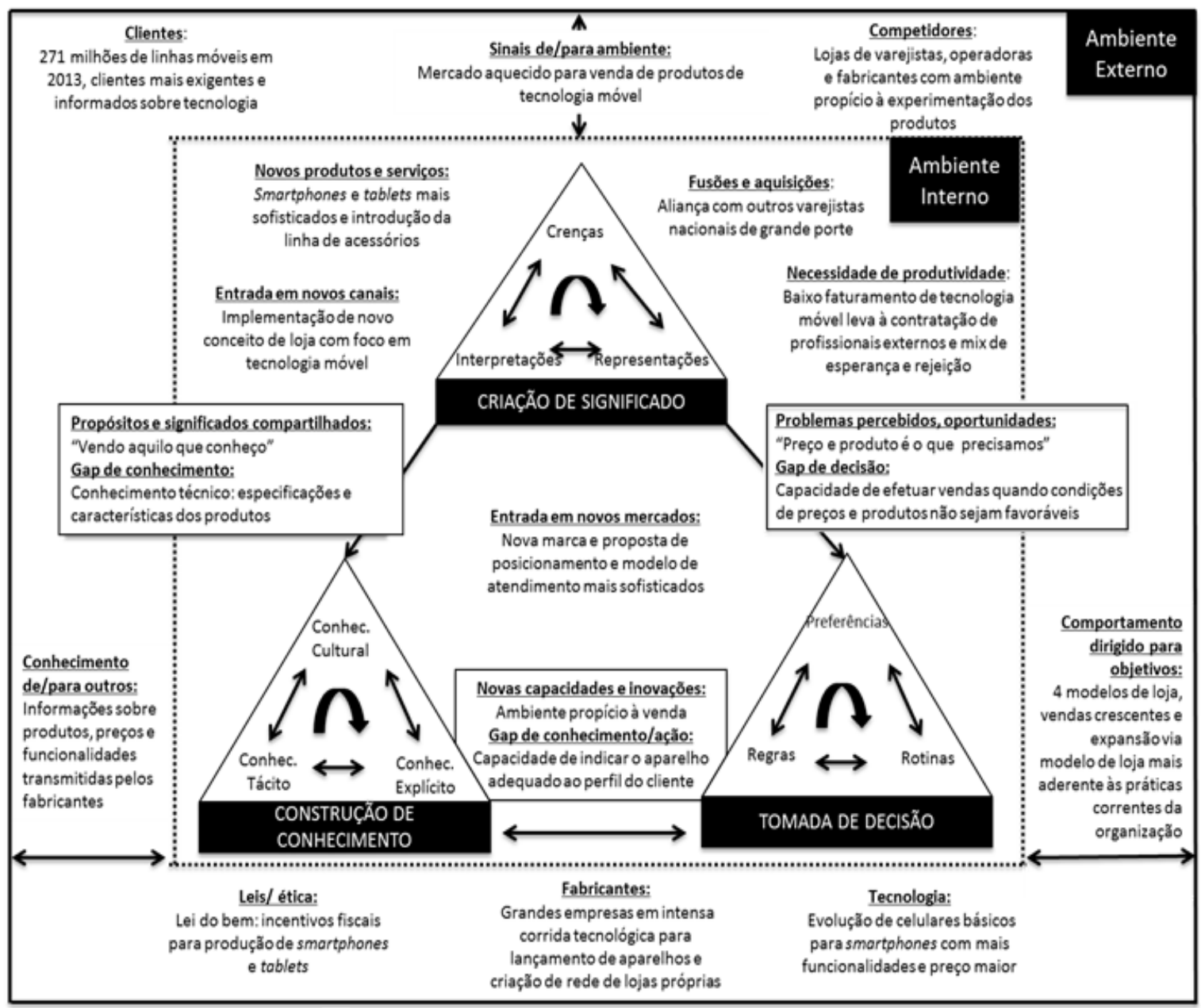

Fonte: Adaptado de $\mathrm{CHOO}$ (2003) incorporando elementos da pesquisa sobre varejo.

Por se tratar de um momento único e particular na história da organização, as conclusões derivadas deste estudo apresentam limitações quanto à capacidade de generalização para outros varejistas, uma vez que a característica específica da organização em questão não foi plenamente considerada e pode ter exercido influência nos resultados obtidos. Este estudo enseja a oportunidade de aprofundamento do tema uso da informação por profissionais de venda do varejo por meio de pesquisas futuras, abordando os seguintes temas como novas tecnologias, a exemplo do Whatsapp, afetam as relações trabalhistas, hierárquicas e processuais no segmento varejista. Outra proposta futura seria analisar como as organizações varejistas podem se apropriar das informações que circulam em seus pontos de venda e institucionalizá-las em conhecimento explícito ao longo da sua cadeia de processos. Finalmente, espera-se que este trabalho possa ser útil na compreensão do como e por que o varejo brasileiro tem usado a informação associada ao processo de vendas.

\section{Referências}

BAXTER, P.; JACK, S. Qualitative case study methodology: study design and implementation for novice researchers. The Qualitative Report, v. 13, n. 4, p. 544-559, 2008. 
BERGERON, P. et al. Working with Information: information management and culture in a professional services organization. Journal of Information Science, v. 32, p. 491-510, 2006.

BRITO, E., VIEIRA, V., \& ESPARTEL, L. A Pesquisa na Área do Varejo: Reflexões e Provocações. RAE, v. 51, n. 6, p. 522 - 527, 2011.

BROWN, S. et al. The changing environment of selling and sales management. Journal of Personal Selling \& Sales Management, v. 25, n. 2, p. 105-111, 2005.

CARVALHO, R. B. et al. Links between competence management and the knowing organization. Journal of Learning and Intellectual Capital, v. 4, n. 3, p. 222-239, 2007.

$\mathrm{CHOO}, \mathrm{C}$. W. The art of scanning the environment. Bulletin of the American Society for Information Science and Technology, v. 25, n. 3, p. 21-24, 1999.

CHOO, C. W. A organização do conhecimento. 3. ed. São Paulo: Editora Senac, 2003.

INTERNATIONAL DATA CORPORATION (IDC). Estudo da IDC aponta que mercado brasileiro de celulares encerrou 2013 com a marca recorde de 67,8 milhões de unidades comercializadas. 2014. Disponível em: <http://www.idcbrasil.com.br/releases/news.aspx?id=1613>. Acesso em: 17 mar.2016.

KOTLER, P.; KELLER, K. Administração de marketing. 12. ed. São Paulo: Pearson, 2006.

LEVY, M.; WEITZ, B. Retailing management. New York: McGraw-Hill Irvin, 2012.

NONAKA, I.; TAKEUCHI, H. Criação de conhecimento na empresa. São Paulo: Campus, 1997.

ROSEBLOON, B. Canais de marketing. São Paulo: Atlas, 2002.

SIMON, H.A.; MARCH, J.G. Organizations. 2. ed. Oxford: Blackwell, 1993.

WEICK, K. E. Sensemaking in organizations. Thousand Oaks: Sage, 1995.

WILSON, T. D. On user studies and information needs. Journal of Documentation, v. 62, p. 658-670, 2006.

YIN, R. K. Estudo de caso: planejamento e métodos. Porto Alegre: Bookman, 2009. 